\title{
Experimental Study on Surface Roughness by Using Abrasive Particles
}

\author{
A.K.Chaitanya ${ }^{1}$, D.Kishore Babu ${ }^{2}$, K.V.N.Girish Kumar ${ }^{3}$, K.Prakash ${ }^{4}$. \\ ${ }^{I}$ Assistant Professor, Department Of Mechanical Engineering, PSCMR College of Engineering \& Technology, \\ VJA. \\ ${ }^{2}$ Assistant Professor, Department Of Mechanical Engineering, PSCMR College of Engineering \& Technology, \\ VJA. \\ ${ }^{3}$ Assistant Professor, Department Of Mechanical Engineering, PSCMR College of Engineering \& Technology, \\ VJA. \\ ${ }^{4}$ Assistant Professor, Department Of Mechanical Engineering, PSCMR College Of Engineering \& Technology, \\ VJA.
}

\begin{abstract}
New advancement of technology and never satisfying demands of the civilization are putting huge pressure on the natural fuel resources and these resources are at a constant threat to its sustainability. Surface finish has a vital influence on functional properties such as wear resistance and power loss due to friction on most of the engineering components. Voltage, mesh number, revolutions per minute (rpm) of electromagnet, and percentage weight of abrasives has been identified as important process parameters affecting surface roughness. The experiments were planned using response surface methodology and percentage change in surface roughness $(\triangle \mathrm{Ra})$ was considered as response. Analysis of experimental data showed that percentage change in surface roughness $(\triangle \mathrm{Ra})$ was highly influenced by mesh number followed by percentage weight of abrasives, rpm of electromagnet, and voltage. The process has been investigated extensively in the finishing of cylindrical surfaces. The surface finish was found to improve significantly with an increase in the grain size, relative size of abrasive particles vis-à-vis the iron particles, feed rate and current. Super finishing is a micro-finishing process that produces a controlled and smooth surface condition on work pieces. It is not primarily a sizing operation, its major purpose is to produce a surface on a work piece capable of sustaining uneven distribution of a load by improving the geometrical accuracy. The wear life of the parts micro finished to maximum smoothness is extended considerably. According to the design of experimentation, mathematical model for Lapping operation on advance ceramic material is proposed. In order to get minimum values of the surface roughness, optimization of the mathematical model is done and optimal operation of the examined factors is going to be determined. The obtained results will be, according to the experiment plan, valid for the testing of ceramic material by Lapping operation.
\end{abstract}

\subsection{SURFACE FINISHING}

\section{INTRODUCTION}

Surface finishing is a broad range of industrial processes that alter the surface of a manufactured item to achieve a certain property. Finishing processes may be employed to: improve appearance, adhesion or wet ability, solder ability, corrosion resistance, tarnish resistance, chemical resistance, wear resistance, hardness, modify electrical conductivity, remove burrs and other surface flaws, and control the surface friction. In limited cases some of these techniques can be used to restore original dimensions to salvage or repair an item. An unfinished surface is often called mill finish. Surface finishing processes can be categorized by how they affect the work piece:

- Removing or reshaping finishing

- Adding or altering finishing
Mechanical processes may also be categorized together because of similarities the final surface finish.

\section{POLISHING:}

Polishing and buffing are finishing processes for smoothing a work piece's surface using an abrasive and a work wheel or a leather strop. Technically polishing refers to processes that use an abrasive that is glued to the work wheel, while buffing uses a loose abrasive applied to the work wheel. Polishing is a more aggressive process while buffing is less harsh, which leads to a smoother, brighter finish. A common misconception is that a polished surface has a mirror bright finish, however most mirror bright finishes are actually buffed. Polishing is often used to enhance the appearance of an item, prevent contamination of instruments, remove oxidation, 
create a reflective surface, or prevent corrosion in pipes. In metallographic and metallurgy, polishing is used to create a flat, defect-free surface for examination of a metal's microstructure under a microscope. Silicon-based polishing pads or a diamond solution can be used in the polishing process. Polishing stainless steel can also increase the sanitary benefits of stainless steel.The removal of oxidization (tarnish) from metal objects are accomplished using a metal polish or tarnish remover; this is also called polishing. To prevent further unwanted oxidization, polished metal surfaces may be coated with wax, oil, or lacquer. This is of particular concern for copper alloy products such as brass and bronze.

Mechanical properties: The strength of polished products is normally higher than their rougher counterpart owing to the removal of stress concentrations present in the rough surface. They take the form of corners and other defects, which magnify the local stress beyond the inherent strength of the material. Polishing with very fine abrasive differs physically from coarser abrasion, in that material is removed on a molecular level, so that the rate is correlated to the boiling point rather than to the melting point of the material being polished.

\subsection{SELECTION OF ABRASIVES Common}

Abrasive Materials

Synthetic Diamond

Cubic Boron Nitride (CBN)

Aluminium Oxide

Silicon Carbide (Sic)

\section{Aluminium Oxide:}

Aluminium oxide is used for its hardness and strength. It is widely used as an abrasive, including as a much less expensive substitute for industrial diamond. Many types of sandpaper use aluminium oxide crystals. In addition, its low heat retention and low specific heat make it widely used in grinding operations, particularly cut-off tools. As the powdery

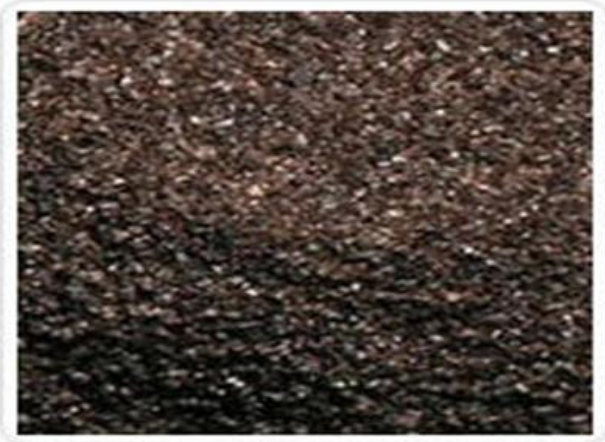

Fig1: Aluminium Oxide Grit
Abrasive mineral aloxite, it is a major component, along with silica, of the cue tip "chalk" used in billiards. Aluminium oxide powder is used in some CD/DVD polishing and scratch-repair kits. Its polishing qualities are also behind its use in toothpaste. Aluminum oxide can be grown as a coating on aluminum by anodizing or by plasma electrolytic oxidation (see the "Properties" above). Both the hardness and abrasion-resistant characteristics of the coating originate from the high strength of aluminum oxide, yet the porous coating layer produced with conventional direct current anodizing procedures is within a 60-70 Rockwell hardness $\mathrm{C}$ range which is comparable only to hardened carbon steel alloys, but considerably inferior to the hardness of natural and synthetic corundum. Instead, with plasma electrolytic oxidation, the coating is porous only on the surface oxide layer while the lower oxide layers are much more compact than with standard DC anodizing procedures and present a higher crystalline due to the oxide layers being re melted and densified to obtain $\alpha-\mathrm{Al} 2 \mathrm{O} 3$ clusters with much higher coating hardness values circa 2000 Vickers hardness. Alumina is used to manufacture tiles, which are attached inside pulverized fuel lines, and flue gas ducting on coal fired power stations to protect high wear areas. They are not suitable for areas with high impact forces as these tiles are brittle and susceptible to breakage.

1.3 NEED FOR SUFACE FINISHING: Surface finish, or texture, can be viewed from two very different perspectives. From the machinist's point of view, texture is a result of the manufacturing process. By altering the process, the texture can be changed. From the part designer's point of view, surface finish is a condition that affects the functionality of the part to which it applies. By changing the surface finish specification, the part's functionality can be altered-and hopefully, improved. Bridging the gap between these two perspectives is the manufacturing engineer, who must determine how the machinist is to produce the surface finish specified by the design engineer. The methods one chooses to measure surface finish, therefore, depend upon perspective, and upon what one hopes to achieve.

- 1.4 SCOPE OF SURFACE FINISHING: Optimize conventional wet processes to achieve near zero discharge and risk -Improve the efficiency and performance of conventional surface finishing processes to reduce chemical usage, worker exposure risk and waste generation, while maintaining or improving surface finish quality, processing speed and capacity. 
- Improve process monitoring and control systems - Automate surface finishing process lines. For manual process lines, deploy state-ofthe-art software to enhance information access and process verification.

- Pursue sustainable manufacturing - Use processes and systems that are non-polluting, energy conserving, natural resource conserving, economically efficient, and safe for workers, the community, and consumers.

- Improve energy efficiency -- Use more energy efficient equipment and/or modify manufacturing processes to increase efficiency and reduce energy consumption.

Developing and Implementing New Technology:

- Change to "greener" process chemistries Change to alternative "green" chemistries that can meet surface finishing process requirements while reducing or eliminating the use and generation of hazardous substances.

- Change from "wet" processes to "dry" processes -- Change from conventional surface finishing immersion chemistry solutions to alternative metal deposition technologies (e.g. HVOF or PVD)

- Change substrate materials from finished metals to non-metals -- Change materials and manufacturing processes from metal finishing to non-metals, such as composites or plastics.

- Develop new metal alloys that reduce surface finishing requirements -- Use new metal alloys that provide sufficient corrosion resistance and reduce or eliminate the need for metal finishing using toxic chemical processes (e.g. new stainless steel alloy that can replace steel coated with cadmium).

- Develop nanotechnology -- Use Nano crystalline metal coating processes or using nano material-enhanced metal or non-metal substrates.

\section{METHODOLOGY}

\subsection{Abrasive Finishing Of Rough Surfaces}

Surface finishing can be done with the help of Aluminum oxide abrasives. The abrasives are rotated in the tub. The abrasives are whirled in tub. The resonation is very rapid and the abrasives strike one another causing friction. The work piece dipped in to these abrasives. These abrasives will strike the coarse structure and the excess material is removed from the surface of the work piece. Hence, burrs formed are deposited in the abrasives.

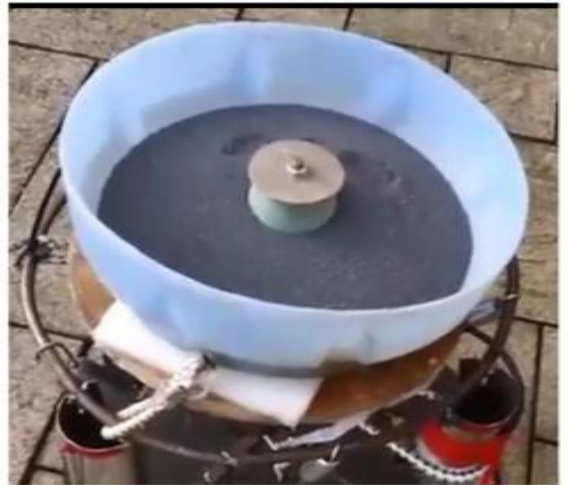

Fig 2

\subsection{ALUMINUM OXIDE ABRASIVES}

Aluminum oxide is used for its hardness and strength. It is widely used as an abrasive, including as a much less expensive substitute for industrial diamond. Many types of sandpaper use aluminum oxide crystals. In addition, its low heat retention and low specific heat make it widely used in grinding operations, particularly cutoff tools. As the powdery abrasive mineral aloxite, it is a major component, along with silica, of the cue tip"chalk" used in billiards. Aluminum oxide powder is used in some CD/DVD polishing and scratch-repair kits. Its polishing qualities are also behind its use in toothpaste.

\subsection{WORK PIECE MATERIALS: STAINLESS STEEL:}

In metallurgy, stainless steel, also known as inox steel or inox from French inoxydable (in oxidizable), is a steel alloy with a minimum of $10.5 \%{ }^{[1]}$ chromium content by mass. Stainless steel is notable for its corrosion resistance, and it is widely used for food handling and cutlery among many other applications.

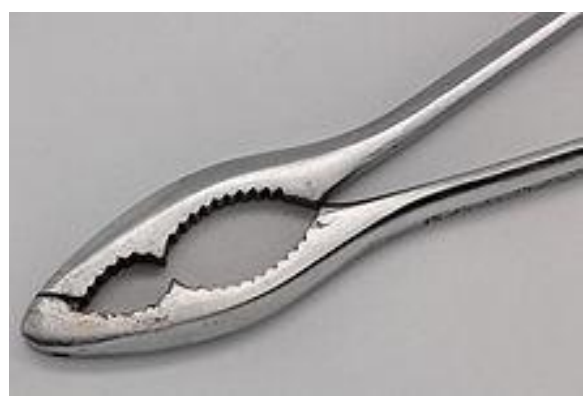

Stainless steel does not readily corrode, rust or stain with water as ordinary steel does. However, it is not fully stain-proof in low-oxygen, highsalinity, or poor air-circulation environments. ${ }^{[2]}$ There are various grades and surface finishes of stainless steel to suit the environment the alloy must endure. Stainless steel is used where both the 
properties of steel and corrosion resistance are required.

BRASS: Brass is a metal alloy made of copper and zinc; the proportions of zinc and copper can be varied to create a range of brasses with varying properties. It is a substitution alloy: atoms of the two constituents may replace each other within the same crystal structure.

\section{IRON AND ITS OXIDES:}

Iron chemical compounds have many uses. Iron oxide mixed with aluminum powder can be ignited to create a termite reaction, used in welding and purifying ores. Iron forms binary compounds with the halogens and the chalcogens. Among its organo metallic compounds is ferrocene, the first sandwich compound discovered.

\subsection{Surface Finish Measurement:}

Surface finish measurement, sometimes called surface texture measurement, is the characterizing of a surface's quality or conformance to expectations (for example, to an engineering specification) through measurement of its variations in local height over a given distance. There are several aspects of the surface to be consideredered.

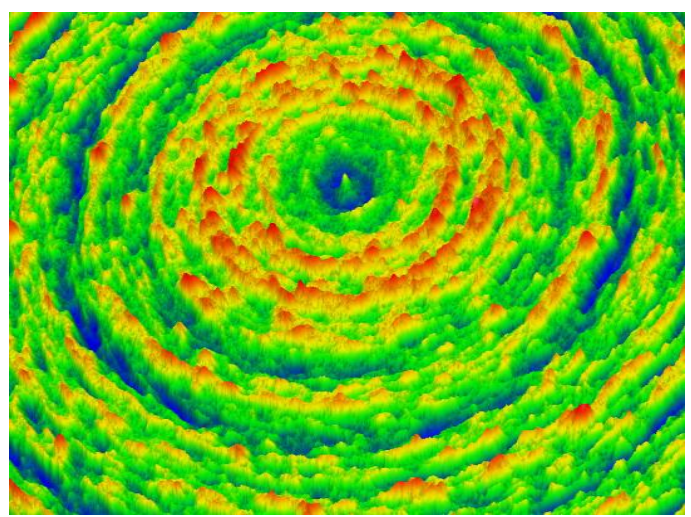

Fig3Ground Surface Finish Measurement Surface Roughness vs. Surface Finish:

Surface roughness measurement is a quantitative assessment of very closely occurring surface irregularities, and is sometimes used interchangeably with the term surface finish measurement. There is a difference in context, however: while surface roughness is a general term about the amount of surface variation (at a very small scale) on any given surface, whether natural, man-made or found, "surface finish" is a term implying a surface that has been deliberately modified or engineered, with an end in mind.

\subsection{OPERATING PARAMETERS:}

Parameters are the quantitative methods used to describe and compare surface characteristics. These are defined by the algorithms that are used to turn raw measurement data into a numerical value. Although more than 100 parameters exist, machinists have traditionally relied upon just one or two parameters. Currently, Ra, or average roughness, is the parameter most widely specified and measured. The algorithm for Ra calculates the average height of the entire surface, within the sampling length, from the mean line. It serves as an effective means of monitoring process stability, which explains why it is the predominant parameter in use today.

\section{THEORETICAL CALCULATIONS AND EXPERIMENTAL ANALYSIS 3.1THEORITICAL CALCULATIONS;}

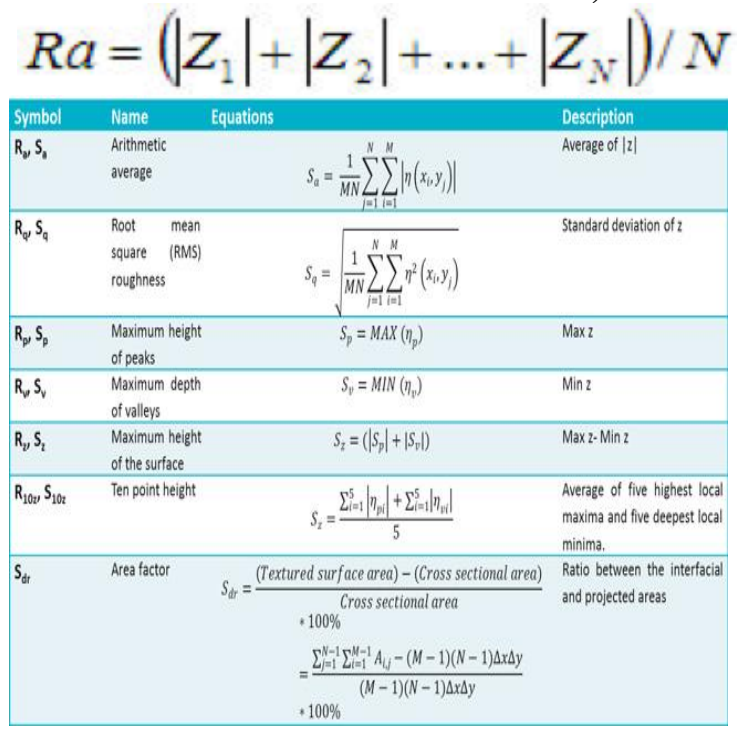

\section{Equivalent Ra values for Surface Finish Grade} Numbers:

Older drawings may use roughness grade numbers to indicate Ra values. The following table is given in ISO 1302:1992.

\begin{tabular}{|c|c|c|c|c|c|}
\hline $\begin{array}{c}\text { Roughness } \\
\text { N } \\
\text { ISO } \\
\text { Grade } \\
\text { Numbers }\end{array}$ & $\begin{array}{l}\text { Roughness } \\
\text { values Ra } \\
\text { micrometres } \\
(\mu \mathrm{m})\end{array}$ & $\begin{array}{c}\text { Roughness } \\
\text { values Ra } \\
\text { micro } \\
\text { inches } \\
(\mu \text { in. })\end{array}$ & RMS & $\begin{array}{c}\text { CLA } \\
(\mu \text { in. }) \\
\text { Centre } \\
\text { Line } \\
\text { Avg. }\end{array}$ & $\begin{array}{c}\text { Rt } \\
\text { Roughness, } \\
\text { microns }\end{array}$ \\
\hline N12 & 50 & 2000 & 2200 & 2000 & 200 \\
\hline N11 & 25 & 1000 & 1100 & 1000 & 100 \\
\hline N10 & 12.5 & 500 & 550 & 500 & 50 \\
\hline N9 & 6.3 & 250 & 275 & 250 & 25 \\
\hline N8 & 3.2 & 125 & 137.5 & 125 & 13 \\
\hline N7 & 1.6 & 63 & 64.3 & 63 & 8.0 \\
\hline N6 & 0.8 & 32 & 32.5 & 32 & 4.0 \\
\hline N5 & 0.4 & 16 & 17.6 & 16 & 2.0 \\
\hline $\mathrm{N} 4$ & 0.2 & 8 & 8.8 & 8 & 1.2 \\
\hline N3 & 0.1 & 4 & 4.4 & 4 & 0.8 \\
\hline N2 & 0.05 & 2 & 2.2 & 2 & 0.5 \\
\hline N1 & 0.025 & 1 & 1.1 & 1 & 0.3 \\
\hline
\end{tabular}

$\mathrm{L}=$ evaluation length

$\mathrm{Z}(\mathrm{x})=$ the profile height function 

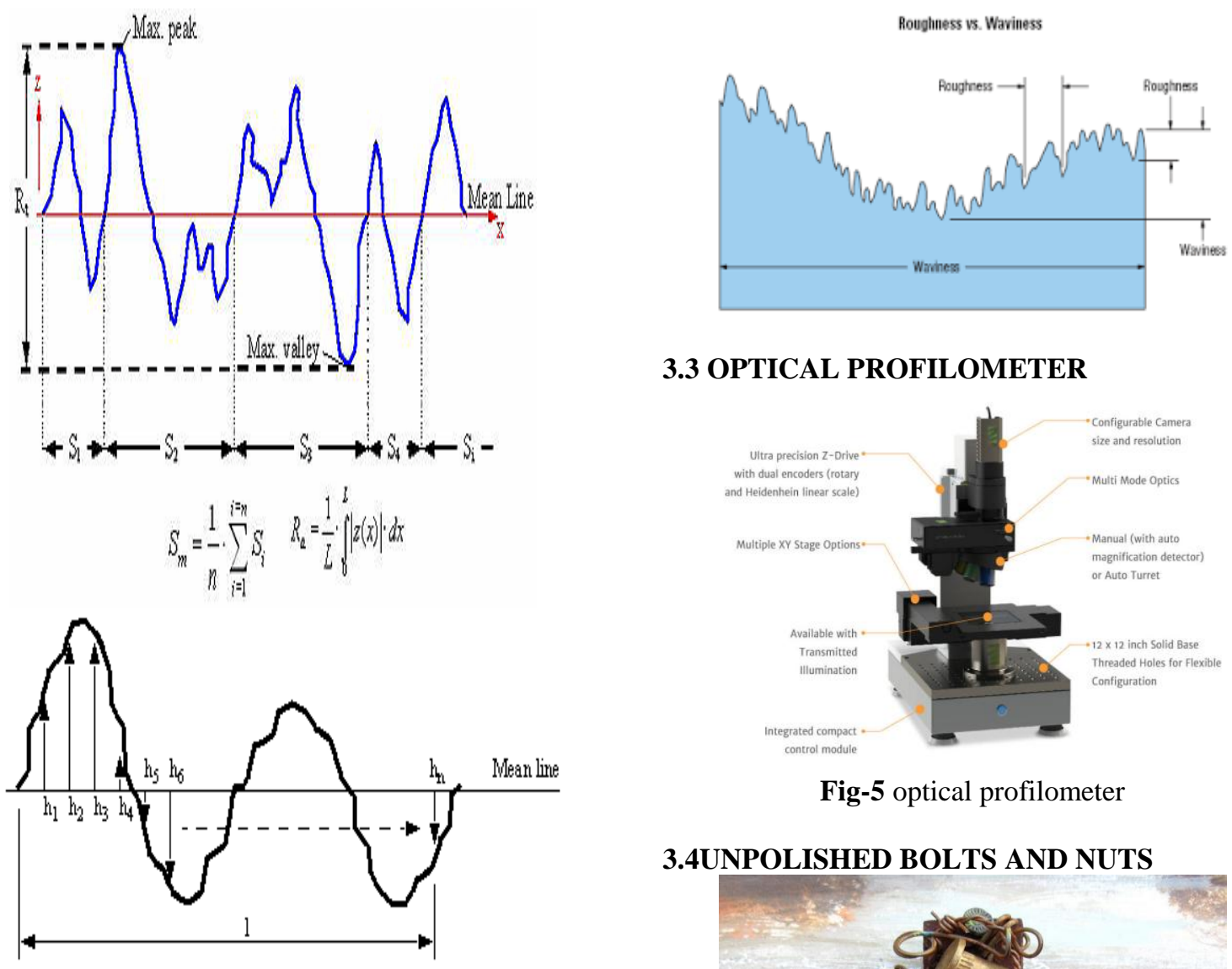

$$
R M S=R_{q}=\sqrt{\frac{h_{1}^{2}+h_{2}^{2}+h_{3}^{2}+\ldots+h_{n}^{2}}{n}}
$$

**Note: This value is typically $11 \%$ higher than CLA or $\mathrm{R}_{\mathrm{a}}$

\subsection{Experimental analysis:}

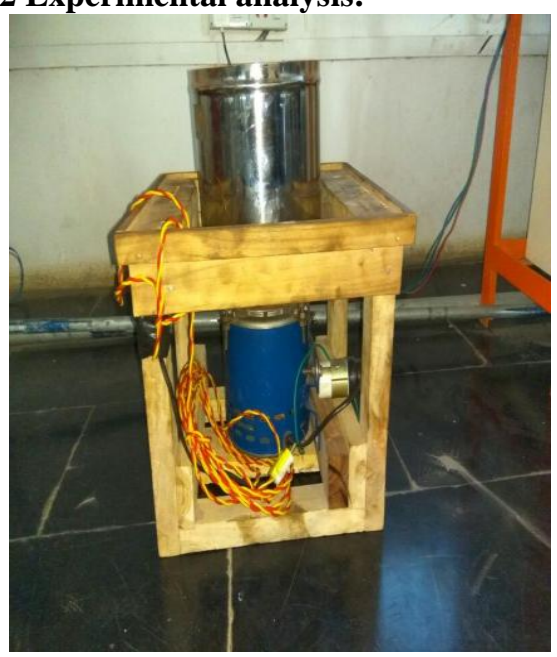

Fig-4 fabricated machine

\subsection{OPTICAL PROFILOMETER}

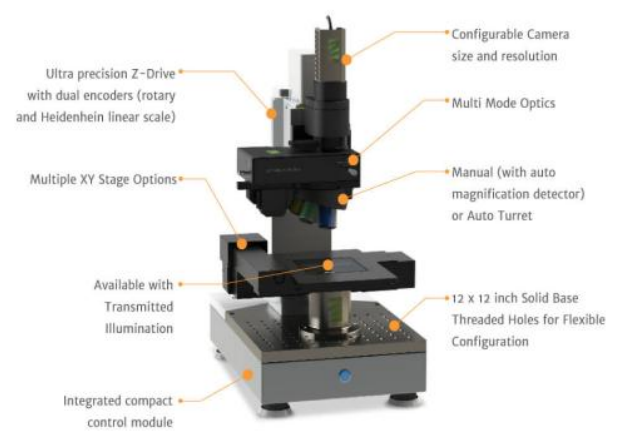

Fig-5 optical profilometer

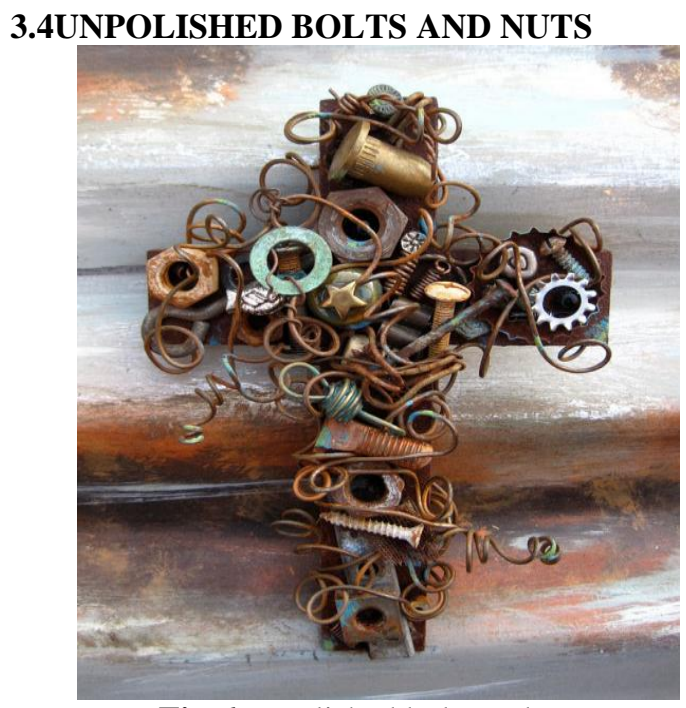

Fig-6 unpolished bolts and nuts

\subsection{POLISHED NUTS AND BOLTS:}

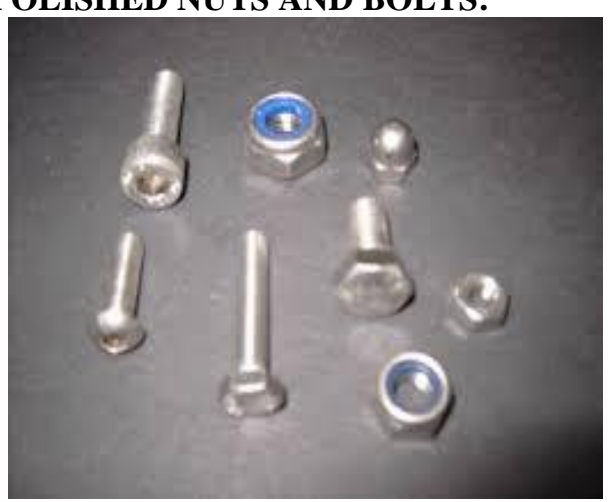



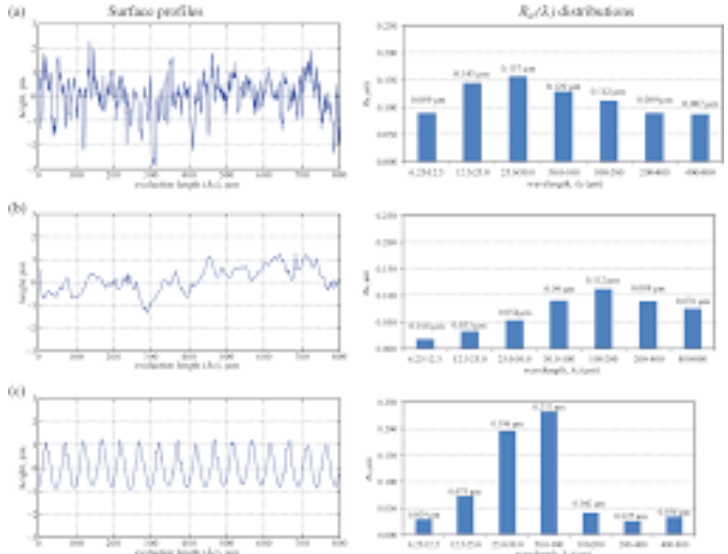

III. RESULTS AND DISCUSSIONS

Table IV - Mean (SD) of roughness values in different parameters for Y-TZP sufface treatments. "The same superscripted

letters indicate no sienificant differences in the same column (Tukey's test, $\alpha=0.05$ ).
[Tabela IV - Média (DP) dos valores de rugosidade nos diferentes parâmetros para os diferentes tratamentos de superficie da Y-TZP. "Mesma letras sobrescritas indicam não haver diferença estatisticamente signifcante para mesma colum (Teste de Tukey, $\alpha=0,05$ ).

\begin{tabular}{|c|c|c|c|c|c|c|c|}
\hline Groups & $\operatorname{Ra}(\mu \mathrm{m})$ & $\mathrm{Rq}(\mu \mathrm{m})$ & $\mathrm{Rz}(\mu \mathrm{m})$ & $\mathrm{X}$-crossing & $\operatorname{Mr} 1(\%)$ & $\operatorname{Mr} 2(\%)$ & $\operatorname{Sdr}(\%)$ \\
\hline A & $0.11(0.01)^{\mathrm{i}}$ & $0.15(0.01)^{j}$ & $1.57(0.1)^{j}$ & $220(14)^{H i}$ & $8.3(0.2)^{\text {fit }}$ & $86.6(0.6)^{\mathrm{h}}$ & $1.6(0.1)^{\frac{1}{3}}$ \\
\hline B & $0.24(0.01)^{\mathrm{h}}$ & $0.30(0.01)^{\mathrm{min}}$ & $2.7(0.3)^{i}$ & $367(17)^{x d}$ & $10.5(0.3)^{b c}$ & $90.9(0.4)^{\text {bo }}$ & $13.8(0.9)$ \\
\hline C & $0.28(0.01)^{\text {th }}$ & $0.35(0.02)^{\text {Hi }}$ & $3.8(0.3)^{6 t+1}$ & $348(17)^{d d}$ & $9.0\left(0.2^{\text {def }}\right.$ & $88.9(0.7)^{e f}$ & $17.1(1.1)^{\mathrm{b}}$ \\
\hline D & $0.46(0.02)^{c d}$ & $0.56(0.02)^{\text {be }}$ & $5.6(0.6)^{k}$ & $266(40)^{\mathrm{f}}$ & $8.4(0.4)^{4 f t}$ & $89.0(0.3)^{e^{f}}$ & $24.5(0.9)^{20}$ \\
\hline $\mathrm{E}$ & . & - & - & - & - & - & - \\
\hline $\mathrm{F}$ & $0.44(0.02)^{\mathrm{cd}}$ & $0.58(0.03)^{e}$ & $5.4(0.6)^{d d}$ & $261(13)^{\text {th }}$ & $7.3(0.4)^{a}$ & $8.1(0.3)^{i}$ & $23.8(1.4)^{d 6}$ \\
\hline G & $0.72(0.03)^{2}$ & $0.92(0.06)^{b}$ & $6.9(0.6)^{\mathrm{b}}$ & $186(9)^{i}$ & $5.9(0.6)^{i}$ & $87.6(0.6)^{\text {th }}$ & $28.0(1.3)^{b}$ \\
\hline H & $0.23(0.01)^{\mathrm{h}}$ & $0.29(0.01)^{\mathrm{i}}$ & $2.9(0.2)^{\mathrm{hi}}$ & $428(17)^{a}$ & $11.5(0.9)^{a}$ & $91.4(0.8)^{d}$ & $16.1(0.9)^{k}$ \\
\hline I & $0.28(0.01)^{\mathrm{at}^{\mathrm{n}}}$ & $0.35(0.02)^{t^{m}}$ & $4.7(0.5)^{\text {diff }}$ & $379(22)^{x}$ & $9.3(0.3)^{d}$ & $91.0(0.6)^{\text {bb }}$ & $20.0(0.9)^{3}$ \\
\hline $\mathrm{J}$ & $0.42(0.05)^{\text {de }}$ & $0.53(0.06)^{f}$ & $5.3(0.4)^{c d}$ & $311(7)^{e}$ & $9.1(0.4)^{\text {def }}$ & $89.7(0.6)^{\text {de }}$ & $27.0(1.0)^{2}$ \\
\hline $\mathrm{K}$ & $0.21(0.01)^{\mathrm{h}}$ & $0.28(0.01)^{\mathrm{i}}$ & $3.6(0.4)^{\text {in }}$ & $389(21)^{b}$ & $10.5(0.7)^{b}$ & $89.8(0.3)^{d t}$ & $15.2(0.5)^{3}$ \\
\hline L & $0.36(0.01)^{e f}$ & $0.46(0.04)^{\frac{1 t}{t z}}$ & $4.5\left(0.6^{\text {deth }}\right.$ & $336(21)^{\text {de }}$ & $8.9(0.2)^{\text {def }}$ & $90.1(0.7)^{\mathrm{kd}}$ & $23.1(0.6)^{e}$ \\
\hline M & $0.56(0.03)^{b}$ & $0.75(0.05)^{c}$ & $6.8(0.6)^{\mathrm{b}}$ & $248(23)^{\text {th }}$ & $9.6(0.5)^{d d}$ & $90.8(0.6)^{\text {th }}$ & $26.3(1.2)^{b}$ \\
\hline $\mathrm{N}$ & - & - & - & - & - & - & - \\
\hline 0 & $0.53(0.05)^{b}$ & $0.66(0.09)^{d}$ & $6.6(0.6)^{b}$ & $226(16)^{ \pm}$ & $7.0(0.8)^{\mathrm{t}}$ & $87.2(0.9)^{t h}$ & $25.2(1.5)^{c}$ \\
\hline P & $0.75(0.09)^{2}$ & $1.02(0.13)^{a}$ & $7.7(1.3)^{2}$ & $183(13)^{i}$ & $7.6(0.5)^{\text {th }}$ & $88.0(0.8)^{t^{8}}$ & $28.8(1.0)^{1}$ \\
\hline$Q$ & $0.22(0.01)^{\mathrm{h}}$ & $0.28(0.01)^{\mathrm{i}}$ & $2.7(0.2)^{\mathrm{i}}$ & $436(36)^{a}$ & $11.0(0.4)^{35}$ & $91.0(0.6)^{\text {th }}$ & $16.3(0.7)^{\mathrm{k}}$ \\
\hline R & $0.31(0.02)^{\frac{1}{8}}$ & $0.38(0.02)^{z^{n}}$ & $4.2(0.4)^{\text {ef }}$ & $374(23)^{x}$ & $9.4(0.6)^{d}$ & $90.4(0.3)^{3 \text { ind }}$ & $21.3(1.3)^{t}$ \\
\hline $\mathrm{s}$ & $0.49(0.05)^{\mathrm{j}^{\mathrm{x}}}$ & $0.61(0.07)^{\text {de }}$ & $5.1\left(0.6^{d d^{d e}}\right.$ & $254(14)^{\text {tath }}$ & $9.2(0.5)^{d e}$ & $91.2(0.4)^{2}$ & $26.4(0.9)^{b}$ \\
\hline
\end{tabular}

Surface texture of a part or a product has significant effects on its functionality, physicalmechanical properties and visual appearance. In particular for miniature products, the implication of surface quality becomes critical owing to the presence of geometrical features with micro/nanoscale dimensions. Qualitative and quantitative assessments of surface texture are carried out predominantly by profile parameters, which are often insufficient to address the contribution of constituent spatial components with varied amplitudes and wavelengths. In this context, this article presents a novel approach for advanced measurement and analysis of profile average roughness $\left(R_{a}\right)$ and its spatial distribution at different wavelength intervals. The applicability of the proposed approach was verified for three different surface topographies prepared by grinding, laser micro-polishing and micro-milling processes. From the measurement and analysis results, $R_{a}(\lambda)$ spatial distribution was found to be an effective measure of revealing the contributions of various spatial components within specific wavelength intervals towards formation of the entire surface profile. In addition, the approach was extended to the measurement and analysis of areal average roughness $S_{a}(\lambda)$ spatial distribution within different wavelength intervals. Besides, the proposed method was demonstrated to be a useful technique in developing a functional correlation between a manufacturing process and its corresponding surface profile.

\section{REFERENCES}

[1] Boothroyd, G. and Knight, W. A., (1989), Fundamentals of Machining and Machine Tools, Second Edition, Marcel Dekker Inc., New York.

[2] Charisis, D., Koutayas, S.O., Kamposiora, P., Doukoudakis, A. Spectrometric evaluation of the influence of different backgrounds on the colour of glassinfiltrated ceramic veneers. Eur $\mathrm{J}$ Esthet Dent. 2006;1:142-156.

[3] Brosheer, B. C., (1948), "How Smooth is Smooth? Part-I, Specification and Evaluation of Machined Finishes", American Machinist, McGrow-Hill Publishing Company, pp. 97-112.

[4] CIE 1971: International Commission on Illumination. Colorimeter: Illumination. Publication CIE No. 15 (E-1.3.1), . 